\section{Identification of Turf Bermudagrasses on the Oklahoma State University Baseball Field and Three Experimental Clones as Revealed with Simple Sequence Repeat Markers}

\author{
Tilin Fang ${ }^{1}$, Yanqi Wu ${ }^{1,4}$, Shiva Makaju ${ }^{1}$, Todd Tribble ${ }^{2}$, \\ Dennis L. Martin ${ }^{3}$, and Justin Q. Moss ${ }^{3}$
}

AdDitional INDEX wORDs. Cynodon sp., molecular marker, breeding, genotyping

SUMMARY. Turfgrass varietal identification is critical and allows turfgrass professionals to manage the turf based on the cultural requirements of the variety. On the Oklahoma State University (OSU) Baseball Field (OSUBF) in Stillwater, OK, some bermudagrass (Cynodon sp.) plants exhibited desirable traits but their exact identities were unknown due to the installation of multiple varieties over time. Accordingly, the major objective of this study was to identify if the desirable bermudagrass plants were from commercially available known varieties. Recently, the OSU turf bermudagrass breeding program developed and entered three fairway-type clonal bermudagrasses in the 2013 National Turfgrass Evaluation Program (NTEP) bermudagrass trial: OKC 1131, OKC 1163, and OKC 1302. The secondary objective was to create molecular marker profiles for these three experimental lines. Five OSUBF samples were analyzed using simple sequence repeat (SSR) markers, along with 24 clonal, commercially available turf bermudagrass varieties widely used in Oklahoma, the three OSU experimental clones, six randomly selected single plants from 'Riviera', and two controls for common bermudagrass (Cynodon dactylon) and african bermudagrass (Cynodon transvaalensis). SSR marker genotyping data indicated that the five OSUBF plants were clones of an identical bermudagrass. The OSUBF bermudagrass had the same fingerprint as 'Astro-DLM' bermudagrass for 14 out of 16 SSRs genotyped. Fifteen out of 30 additional SSR markers also showed differences between the OSUBF bermudagrass and 'Astro-DLM'. The three OSU experimental clones were different from each other and had different fingerprints from the other tested varieties based on SSR profiles, indicating they are new breeding lines. These four distinct lines have potential to be released as new varieties if they demonstrate superior turf quality traits and adaptation over time.

$\mathrm{I}$ n the U.S. transition zone, turf bermudagrasses have been increasingly used on sports fields as they possess excellent traffic and drought tolerance, less damage from diseases and insects, and quicker recovery from damage than many other turfgrasses. Turf bermudagrass has been used on the OSUBF in Stillwater, $\mathrm{OK}$, for decades. However, the identities of bermudagrasses grown on the OSUBF have been lost due This research was sponsored in part by the U.S. Golf
Association, U.S. Department of Agriculture Specialty
Crops Research Initiative award 2010-51181-21064,
and Oklahoma Agricultural Experiment Station.
${ }^{1}$ Plant and Soil Sciences Department, Oklahoma State
University, Stillwater, OK 74078
${ }^{2}$ Athletic Department, Oklahoma State University,
Stillwater, OK 74078
${ }^{3}$ Horticulture and Landscape Architecture Depart-
ment, Oklahoma State University, Stillwater, OK
74078
${ }^{4}$ Corresponding author. E-mail: yanqi.wu@okstate. edu. to the use of multiple varieties over several years. Seeded bermudagrasses ('Guymon'), variety not specified common bermudagrass ('Cheyenne', 'JackPot', 'NuMex Sahara', and 'Riviera'), as well as vegetatively propagated bermudagrass ('Patriot') have all been planted on the OSUBF at various times from 1987 to date (D. L. Martin, unpublished data). 'Patriot' and 'Riviera' were developed and released by the Oklahoma Agricultural Experiment Station. 'Patriot' is a clonally propagated $F_{1}$ hybrid from a cross of common bermudagrass 'Tifton 10' and an OSU african bermudagrass selection, whereas $\mathrm{Ri}$ viera bermudagrass is a synthetic variety derived from the intercrossing of three clonal parent plants selected on the basis of turf quality and transition zone adaptation (Taliaferro et al., 2004a, 2004b).

To have suitable bermudagrass sod for repair of damaged spots on the OSUBF, a mini sod farm has been established and maintained on site. Bermudagrass plants in one area of the mini sod farm have been observed to show favored traits, including allowing for successful establishment of overseeded perennial ryegrass (Lolium perenne) in the fall and excellent transition back to bermudagrass in the early summer. However, the identity of the specific bermudagrass(es) of this area is unknown.

In 2013 , three promising vegetatively propagated experimental bermudagrass lines developed by the OSU turf bermudagrass breeding program were entered in the 2013 NTEP bermudagrass trial to allow for testing over a wide geographic area. DNA fingerprints to identify these bermudagrass entries have not been established.

Identification of bermudagrass varieties was challenging until DNA molecular markers were developed, providing powerful identification tools over the last several years. For example, using II SSR markers, 32 commercially released clonal varieties and OSU experimental lines in bermudagrass were identified by Wang et al. (2010). SSR markers differentiated 'Tifgreen' bermudagrass and its mutation derived varieties (HarrisShultz et al., 2011). In this study, the objectives were to use SSR markers to 1) determine if the OSUBF selections were the same plant; 2) identify if the grass was one of the U.S. commercially released,

\begin{tabular}{llll}
\hline $\begin{array}{l}\text { Units } \\
\text { To convert U.S. to SI, } \\
\text { multiply by }\end{array}$ & U.S. unit & SI unit & $\begin{array}{l}\text { To convert SI to U.S., } \\
\text { multiply by }\end{array}$ \\
\hline 29,574 & $\mathrm{fl} \mathrm{oz}$ & $\mu \mathrm{L}$ & $3.3814 \times 10^{-5}$ \\
29.5735 & $\mathrm{fl} \mathrm{oz}$ & $\mathrm{mL}$ & 0.0338 \\
2.54 & $\mathrm{inch}(\mathrm{es})$ & $\mathrm{cm}$ & 0.3937 \\
28.3495 & $\mathrm{oz}$ & $\mathrm{g}$ & 0.0353 \\
$2.8350 \times 10^{10}$ & $\mathrm{oz}$ & $\mathrm{ng}$ & $3.5274 \times 10^{-11}$ \\
1 & $\mathrm{ppm}$ & $\mathrm{ng} \cdot \mu \mathrm{L}^{-1}$ & 1 \\
$\left({ }^{\circ} \mathrm{F}-32\right) \div 1.8$ & ${ }^{\circ} \mathrm{F}$ & ${ }^{\circ} \mathrm{C}$ & $\left({ }^{\circ} \mathrm{C} \times 1.8\right)+32$
\end{tabular}


clonally propagated varieties; and 3) verify if the three recent OSU experimental NTEP entries were new, distinct lines.

\section{Materials and methods}

Plant materials. Thirty-two turf bermudagrass plants constituted the first set of plant materials used in identification of the OSUBF bermudagrass plants. Four plugs were taken from sod on the OSUBF mini sod farm on 12 June 2013 and grown in four respective flats for morphological observation in a greenhouse on the OSU Agronomy Research Farm. Five samples were taken from the four flats based on morphological observations and then grown in separate 6-inch pots [designated as OSUBF 1 to 5 (Table 1)]. The first set of plant materials also comprised 16 clonal turf bermudagrass varieties widely used in Oklahoma, three OSU experimental lines (OKC 1131, OKC 1163, and OKC 1302), and six randomly selected single plants from 'Riviera' bermudagrass (Table 1). 'Michigan' and 'Uganda' were included as controls for common bermudagrass and african bermudagrass, respectively (Table 1 ). To obtain the single plants from 'Riviera', $1 \mathrm{~g}$ of seeds were germinated in a pot and 64 individual plants were transplanted into respective containers after growing to the two-leaf stage, from which six plants ['Riviera l' to 'Riviera 6' (Table l)]

Table 1. Selected turf bermudagrass varieties and unknown bermudagrasses on the Oklahoma State University Baseball Field (OSUBF, Stillwater, OK) sod farm that were genotyped using simple sequence repeat markers.

\begin{tabular}{|c|c|c|c|c|}
\hline No. & Name & Species & Chromosomes $(2 n)$ & Original source/reference ${ }^{\mathrm{z}}$ \\
\hline 1 & OSUBF 1 & Cynodon sp. & Unknown & OSUBF sod farm \\
\hline 2 & OSUBF 2 & Cynodon sp. & Unknown & OSUBF sod farm \\
\hline 4 & OSUBF 4 & Cynodon sp. & Unknown & OSUBF sod farm \\
\hline 5 & OSUBF 5 & Cynodon sp. & Unknown & OSUBF sod farm \\
\hline 6 & ‘Astro’' & $\begin{array}{l}\text { Cynodon dactylon } \times \text { Cynodon } \\
\text { transvaalensis }\end{array}$ & 27 & $\begin{array}{l}\text { Tulsa Grass and Sod Co. } \\
\text { (Tulsa, OK) }\end{array}$ \\
\hline 8 & 'U3-NC' & C. dactylon & 36 & Anderson et al. (2001) \\
\hline 9 & 'U3-SIU' & C. dactylon & 36 & Anderson et al. (2001) \\
\hline 10 & 'U3-TGS' & C. dactylon & 36 & Anderson et al. (2001) \\
\hline 11 & 'Premier' & C. dactylon & 36 & Parsons and Lehman (2007) \\
\hline 12 & 'OKC 70-18' & C. dactylon $\times$ C. transvaalensis & 27 & OAES \\
\hline 13 & 'Patriot' & C. dactylon $\times$ C. transvaalensis & 36 & Taliaferro et al. (2004b) \\
\hline 17 & 'OKC 1163’ & C. transvaalensis & Unknown & OAES \\
\hline 18 & 'OKC 1302' & C. dactylon $\times$ C. transvaalensis & Unknown & OAES \\
\hline 19 & 'Midfield' & C. dactylon $\times$ C. transvaalensis & 27 & Pair et al. (1994a) \\
\hline 20 & 'Quickstand' & C. dactylon & 36 & Phillips et al. (1997) \\
\hline 21 & 'Midlawn’ & C. dactylon $\times$ C. transvaalensis & 27 & Pair et al. (1994b) \\
\hline 22 & 'Midiron’ & C. dactylon $\times$ C. transvaalensis & 27 & Alderson and Sharp (1994) \\
\hline 23 & ‘Tifway’ & C. dactylon $\times$ C. transvaalensis & 27 & Burton (1966) \\
\hline 24 & 'Cardinal' & C. transvaalensis & 18 & unknown \\
\hline 25 & 'Riviera l' & C. dactylon & 36 & OAES \\
\hline 26 & 'Riviera 2' & C. dactylon & 36 & OAES \\
\hline 27 & 'Riviera 3' & C. dactylon & 36 & OAES \\
\hline 28 & 'Riviera 4' & C. dactylon & 36 & OAES \\
\hline 36 & 'GN-1' & C. transvaalensis $\times$ C. dactylon & 27 & Brosnan and Deputy (2008) \\
\hline 37 & 'Aussie Green’ & C. transvaalensis $\times$ C. dactylon & 27 & Baldwin et al. (2006) \\
\hline 38 & 'Greenfield' & C. dactylon & 36 & OAES \\
\hline 39 & 'Tifton 10' & C. transvaalensis $\times$ C. dactylon & 54 & Hanna et al. (1990) \\
\hline 40 & 'Astro-DLM' & C. dactylon $\times$ C. transvaalensis & 27 & Tulsa Grass and Sod Co. \\
\hline 41 & 'Celebration' & C. dactylon & 36 & $\begin{array}{l}\text { Sod Solutions (Awendaw, SC), } \\
\quad \text { Riley }(2000)\end{array}$ \\
\hline
\end{tabular}


Table 2. Forty-six simple sequence repeat (SSR) primer pairs (PP) used to genotype the bermudagrass samples and varieties in identifying Oklahoma State University Baseball Field unknown bermudagrass and three experimental varieties.

\begin{tabular}{|c|c|c|c|c|}
\hline No. & SSR PP identity & Repeat motif & Forward primer sequences $\left(5^{\prime}-3^{\prime}\right)$ & Reverse primer sequences $\left(5^{\prime}-3^{\prime}\right)$ \\
\hline 1 & CDCA $31 / 32$ & (CA) $23-(\mathrm{GA}) 12$ & TCCCTGATTCTCTGAAAGGA & CGGTGACATTGAATACCGAG \\
\hline 2 & CDCA $55 / 56$ & $(\mathrm{GT}) 9$ & CGAGTCCATGCCTAACTCAA & ACGGAAGGGTCAGTGGTAAC \\
\hline 3 & CDCA $77 / 78$ & $(\mathrm{GT}) 25$ & GAAGATGTCATCACGATGGG & CGTACGACCGAGTTCTCTGA \\
\hline 4 & CDCA $133 / 134$ & $(\mathrm{AC}) 14-(\mathrm{AAG}) 5$ & CACCCATTACAGTGAGCACC & TGCTTGGAAACAACCTTCTG \\
\hline 5 & CDCA $155 / 156$ & (TC) $16-(\mathrm{AC}) 15$ & CTCCCTCGTCCATTTCATTT & CGTTGGCACTCACTACCAGT \\
\hline 6 & CDCA $379 / 380$ & $(\mathrm{AC}) 7-(\mathrm{GT}) 37$ & AGCACAGGCTTCTTATGCAA & TTATGAAGATAGCCCGGTCC \\
\hline 9 & CDE $127 / 128$ & $(\mathrm{GAG}) 5$ & GGAAAGAATCAAGGACCGAC & GAGCAACTGAGCAAGCAAAG \\
\hline 10 & CDE $215 / 216$ & $(\mathrm{CCG}) 6$ & ACCACAAGCCAAACCCTACT & AAGTCGAGGTTGAGGTGCTT \\
\hline 11 & CDE $375 / 376$ & $($ GGAC) 5 & AGACGTTCAGCGTCGTCTAC & TGCACACATCCAGCTAGTGA \\
\hline 12 & CDCA $491 / 492$ & $(\mathrm{GT}) 12$ & CTTGGTTCTTGGGTCCTTGT & AGCTCAAGCACCATTGTCAG \\
\hline 13 & CDGA $1795 / 1796$ & $(\mathrm{AC}) 5-(\mathrm{AG}) 36$ & TTCGTGGACTCTGGCTATTG & GCCCAGGTAACGTGTTCTTT \\
\hline 14 & CDATG 1889/1890 & (GCT)7-(GAT)7 & AAACGTGAGAGGCTCTTGCT & GTATGACACACGGAAGGACG \\
\hline 18 & CDCA $21 / 22$ & $(\mathrm{AC}) 13-(\mathrm{AG}) 14$ & GGGCCTCCCCTTTTATACAT & GGTAACCAATCAAGGCCACT \\
\hline 19 & CDCA $81 / 82$ & $(\mathrm{TG}) 38$ & CCATATAACGGGTTCAGCCT & TCAAGAGTTCAGCCTCATGC \\
\hline 20 & CDCA $117 / 118$ & (CT)9-(GT)12 & CCCTGCCTCTTCAAGGTAAG & ACAAAGTTCCTCCGATCACC \\
\hline 21 & CDCA $125 / 126$ & (TG) 20 & AAATTGACCCTCCACAAAGC & AGTCAGGGGTTTCCATTTTG \\
\hline 22 & CDCA $139 / 140$ & (CA)42 & TATATGCTCAGACGATGGGC & GACCCGAAGGTGTGATTCTA \\
\hline 23 & CDCA $247 / 248$ & $(\mathrm{GT}) 8$ & TACCTCGCTGGACTGAAGTG & GCAGTAGTCCCACCAACCTT \\
\hline 24 & CDCA $313 / 314$ & (CA) 23 & GGGTCATGAGTCAAATGTGC & CTTTTGTGAGCCAGAAGCAA \\
\hline 25 & CDCA $319 / 320$ & $(\mathrm{AC}) 22$ & CATGTTCCAGACAAGGATGG & GCAACAAACAGCCACAGAAT \\
\hline 26 & CDCA $401 / 402$ & (TC)7-(AG)9-(TG)21 & ACAATCCAGAACGGGAGAAG & GCTCGTTTTGAGCGTTGTAA \\
\hline 27 & CDCA $441 / 442$ & (CA) $14-(\mathrm{GA}) 8$ & ATCAGGAACTTTTGGTTGCC & GTGTGATTGCCCAGTACCAA \\
\hline 28 & CDCA $463 / 464$ & $(\mathrm{CA}) 12-(\mathrm{GA}) 31$ & CAGGAAAACGAGACGAGAGA & CCGGGACGTCAGATATTTTT \\
\hline 37 & CDGA $1583 / 1584$ & $(\mathrm{AG}) 25$ & GTATCGTCATCGTCCTGGTG & TCGGCCAGAAAACCTCTATT \\
\hline 38 & CDGA $1601 / 1602$ & $(\mathrm{GA}) 13$ & CCTGCTGGTCAGAACTCAAC & TATTGGTTGCACCTTCCAGA \\
\hline 39 & CDGA $1697 / 1698$ & $(\mathrm{CT}) 7-(\mathrm{TC}) 10-(\mathrm{GC}) 5$ & AGTGGTCGGTCATCTTCCTC & AACAGCTGGAGCCTAGGAAA \\
\hline 40 & CDGA 1783/1784 & $(\mathrm{CT}) 24$ & ССТССТСССААСАТСТТСТG & GAAATGCATGTTCCTTGCAC \\
\hline 41 & CDATG $1829 / 1830$ & (TCA) 15 & GAATCTGTCGGGCGAATAAT & AAGCTGATGCAGGAGAGGAT \\
\hline 42 & CDATG $1891 / 1892$ & $(\mathrm{TCA}) 6$ & AGACAAAGGGATCACTCGCT & CACCAAGTCCATCAAGGCTA \\
\hline 43 & CDATG 1905/1906 & (TGA)6 & GACTGCTTCACCGAGTACCA & TCCTGAGCGACCTCTTCC \\
\hline 44 & CDATG $2059 / 2060$ & (TGA)6 & ATTAGTGGTTTTTGGGCAGG & TCCAGTCATTCGAGGAATTG \\
\hline 45 & CDAAC $2675 / 2676$ & $(\mathrm{AAC}) 6$ & TAGCCTACCCCAACTTGCTT & GTATACTGGCTTCATGGGCA \\
\hline 46 & CDAAC $2693 / 2694$ & $(\mathrm{GTT}) 6-(\mathrm{TGT}) 9$ & TTGCCTACCAAACACGAAAG & TCCAAACTCGTGTAATTGCC \\
\hline
\end{tabular}

were randomly selected and used in the experiment.

Eight additional clonal varieties [no. 33-40 (Table 1)] and the OSUBF no. I sample formed the second set of plant materials and were genotyped with 16 SSR markers. 'Astro-DLM' was another source of 'Astro' (D.L. Martin, unpublished data). The third set included OKC 1131, OKC 1163, and OKC 1302;
'NorthBridge' and the current four NTEP clonal bermudagrass standards; 'Patriot', 'Latitude 36', 'Tifway', and 'Celebration'. The plants of this third set were genotyped with 16 SSR markers to establish SSR marker profiles for the three OSU experimental clones. All the plants were grown in 6-inch pots and maintained for healthy growth with daily watering and regular fertilization.
DNA isolation. Healthy leaf tissue was sampled from each of the 41 plants (Table 1) grown in the greenhouse. DNA was isolated from fresh leaf tissue following a modified phenol-chloroform extraction method (Nalini and Jawali, 2004). About $1 \mathrm{~g}$ of leaf tissue was cut and frozen in a $-80{ }^{\circ} \mathrm{C}$ freezer, grinded in a tissue homogenizer (Geno/Grinder; SPEX SamplePrep, 


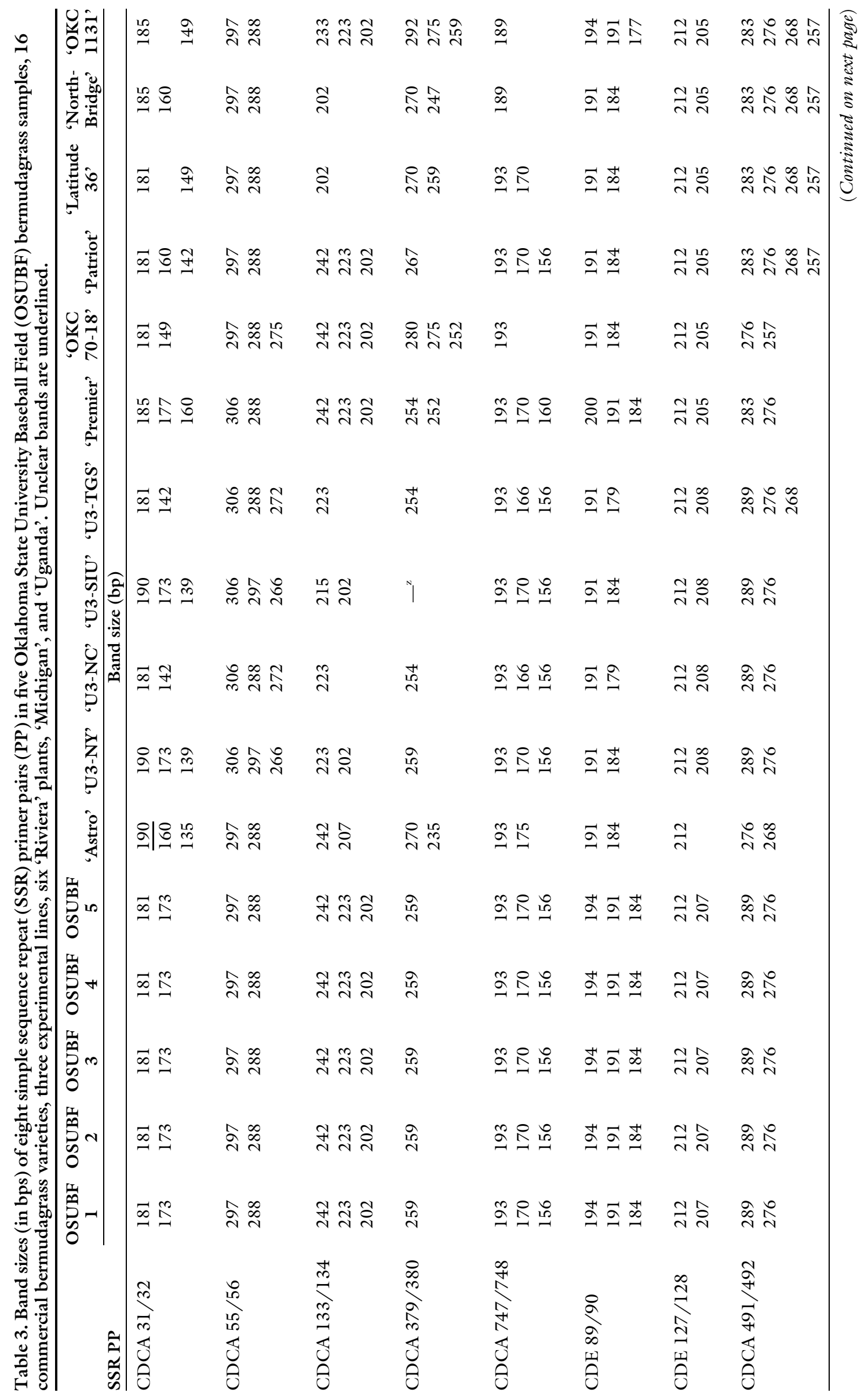




\section{Research Reports}

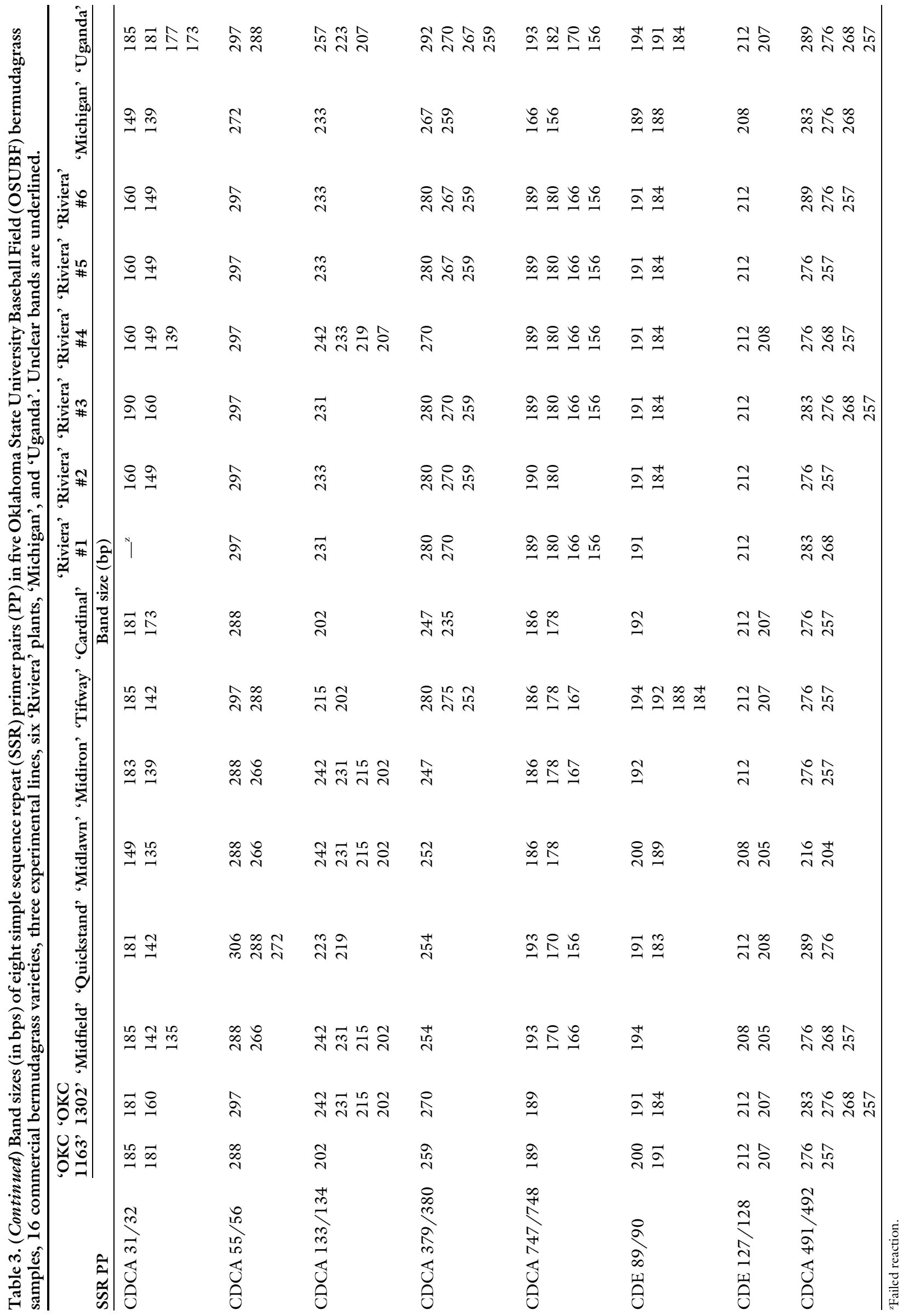


Metuchen, NJ), and vortexed in extraction buffer $(\mathrm{pH}=8.5)$ consisting of $1 \%(\mathrm{w} / \mathrm{v}) \mathrm{N}$-lauroylsarcosine, $100 \mathrm{~mm}$ Tris, $100 \mathrm{~mm}$ sodium chloride, and $10 \mathrm{~mm}$ ethylenediaminetetraacetic acid disodium salt ( $\mathrm{Na}_{2}$ EDTA). The homogenate was emulsified with an equal volume of phenol:chloroform: isoamyl alcohol $(25: 24: 1 \mathrm{v} / \mathrm{v} / \mathrm{v})$ and centrifuged for $10 \mathrm{~min}$ at $14,000 \mathrm{~g}_{\mathrm{n}}$. The supernatant was then transferred to a new tube and mixed with an equal volume of chloroform:isoamyl alcohol $(24: 1 \mathrm{v} / \mathrm{v})$, centrifuged for 5 $\min$ at $14,000 g_{\mathrm{n}}$. The supernatant was then transferred to a new tube containing an equal volume of isopropanol alcohol and $1 / 10$ volume of 3 m sodium acetate $(\mathrm{pH}=5.2)$. The DNA was precipitated by centrifugation for 5 min at $14,000 g_{\mathrm{n}}$ and then was dissolved in 50-100 $\mu \mathrm{L}$ TrisEDTA buffer after the pellet was washed with $1 \mathrm{~mL} \mathrm{70 \%} \mathrm{ethanol} \mathrm{and}$ dried completely. Finally, the DNA was quantified using a spectrophotometer (NanoDrop ND-1000; Thermo Fisher Scientific, Waltham, MA) and diluted to $10 \mathrm{ng} \cdot \mu \mathrm{L}^{-1}$ for polymerase chain reaction (PCR).

SSR MARKERS AND PCR AMPLIFICATION. The 11 SSR primer pairs (PPs) used for varietal identification by Wang et al. (2010) and additional 35 SSR PPs [no. 12-46 (Table 2)] were selected based on the amplification efficiency and polymorphism from initial screening. PCR was conducted following the procedure described by Wang et al. (2010) with minor modifications. Briefly, PCR amplification was performed in a $10 \mu \mathrm{L}$ volume reaction, which consisted of $15 \mathrm{ng}$ DNA, $1 \mu \mathrm{L} 10 \times$ PCR buffer (New England BioLab, Ipswich, MA), $200 \mu \mathrm{M}$ deoxynucleotide, $0.2 \mu \mathrm{M}$ forward primer tailed with Ml3 forward primer sequence $\left(5^{\prime}\right.$ CACGACGTTGTAAAACGACG-3' ), $0.2 \mu \mathrm{M}$ reverse primer, $0.02 \mu \mathrm{M}$ infrared-Ml3 forward primer labeled with either 700 or $800 \mathrm{~nm}$ florescent dye (LI-COR, Lincoln, NE), 0.025 U Taq DNA polymerase (New England BioLab), and water to bring the total volume up to $10 \mu \mathrm{L}$. PCR was performed in a 2720 Thermal Cycler (Applied Biosystems, Foster City, $\mathrm{CA})$ following the program: $5 \mathrm{~min}$ at $95{ }^{\circ} \mathrm{C}$ for denaturation, followed by 14 cycles of $20 \mathrm{~s}$ at $94^{\circ} \mathrm{C}, 60 \mathrm{~s}$ at $58{ }^{\circ} \mathrm{C}, 30 \mathrm{~s}$ at $72{ }^{\circ} \mathrm{C}$, and another 28 cycles of $20 \mathrm{~s}$ at $94^{\circ} \mathrm{C}, 60 \mathrm{~s}$ at $55^{\circ} \mathrm{C}$,
$30 \mathrm{~s}$ at $72{ }^{\circ} \mathrm{C}$, and a $10 \mathrm{~min}$ final extension at $72{ }^{\circ} \mathrm{C}$ (Wang et al., 2010).

GeL eleCtrophoresis AND DATA ANALYSIS. Two plates of PCR products labeled with 700 and $800 \mathrm{~nm}$ were pooled and loaded into a $6.5 \% \mathrm{~KB}$ Plus gel (LI-COR), and separated by running in a LI-COR $4300 \mathrm{DNA}$ Analyzer. Bands from the gel were visually scored and the band size determined using Saga Generation 2 Lite software (LI-COR). In visual scoring of gel images, the bands detected by each SSR PP were recorded for presence (1) and absence $(0)$ for each sample. Jaccard's similarity coefficients were calculated to construct dendrograms using the unweighted pair group method with arithmetic average with the SAHN module of NTSYSpc (Rohlf, 2000) version 2.0 software (Exeter Software, Setauket, NY).

\section{Results and discussion}

In the initial identification, the first set of 32 samples [no. 1-32 (Table 1)] was genotyped with eight SSR markers [no. 1, 2, 4, 6-9, 12 (Table 2)] with two replications of

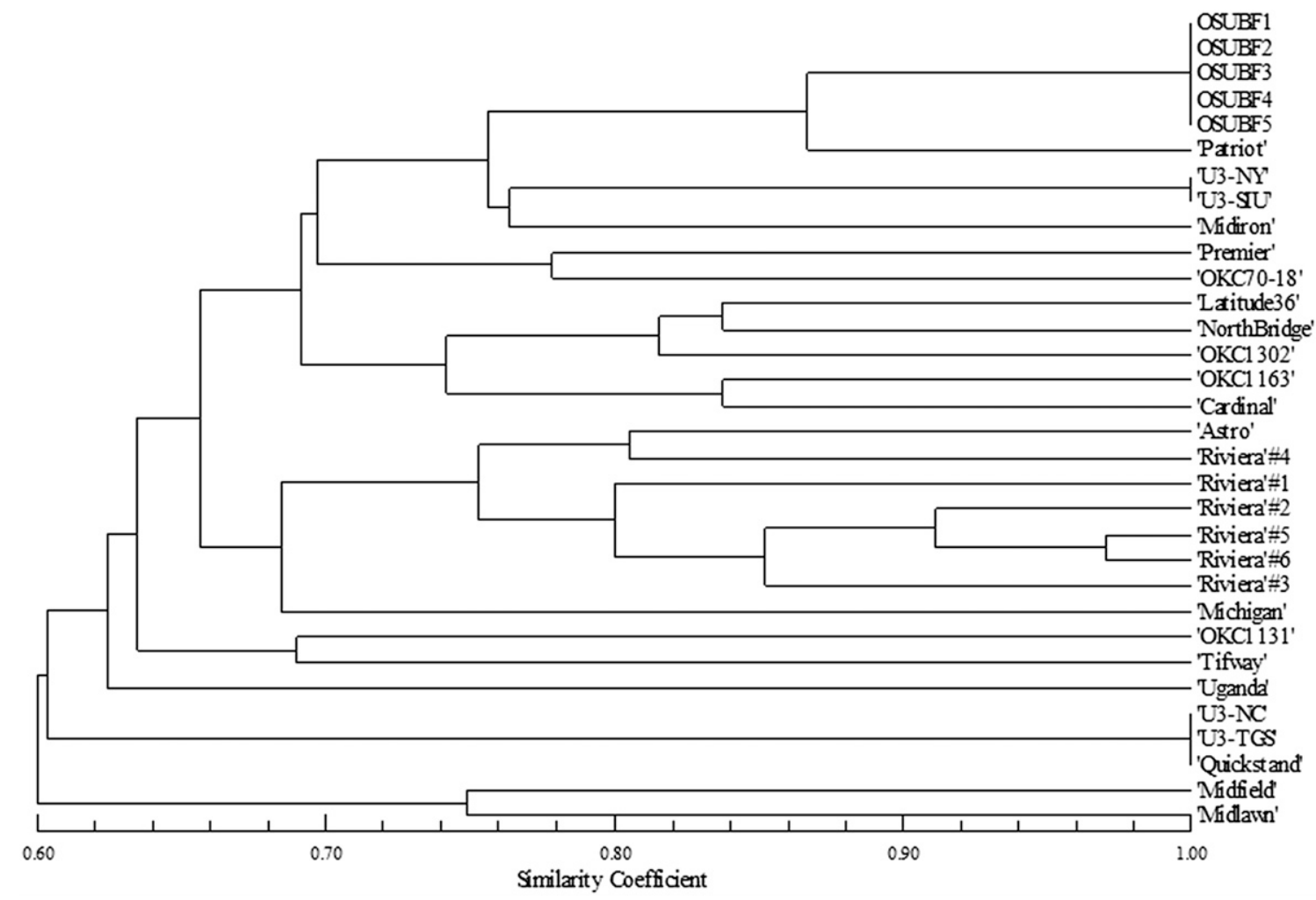

Fig. 1. Dendrogram depicting similarity coefficients of five Oklahoma State University Baseball Field bermudagrass plants (OSUBF 1 to 5), 21 clonal bermudagrass varieties, and six plants from 'Riviera' assessed with eight simple sequence repeat primer pairs. 
Table 4. Band sizes (in bps) in Oklahoma State University Baseball Field (OSUBF) bermudagrass samples and eight commercial bermudagrass varieties amplified with 16 simple sequence repeat (SSR) primer pairs (PP). Unclear bands are underlined.

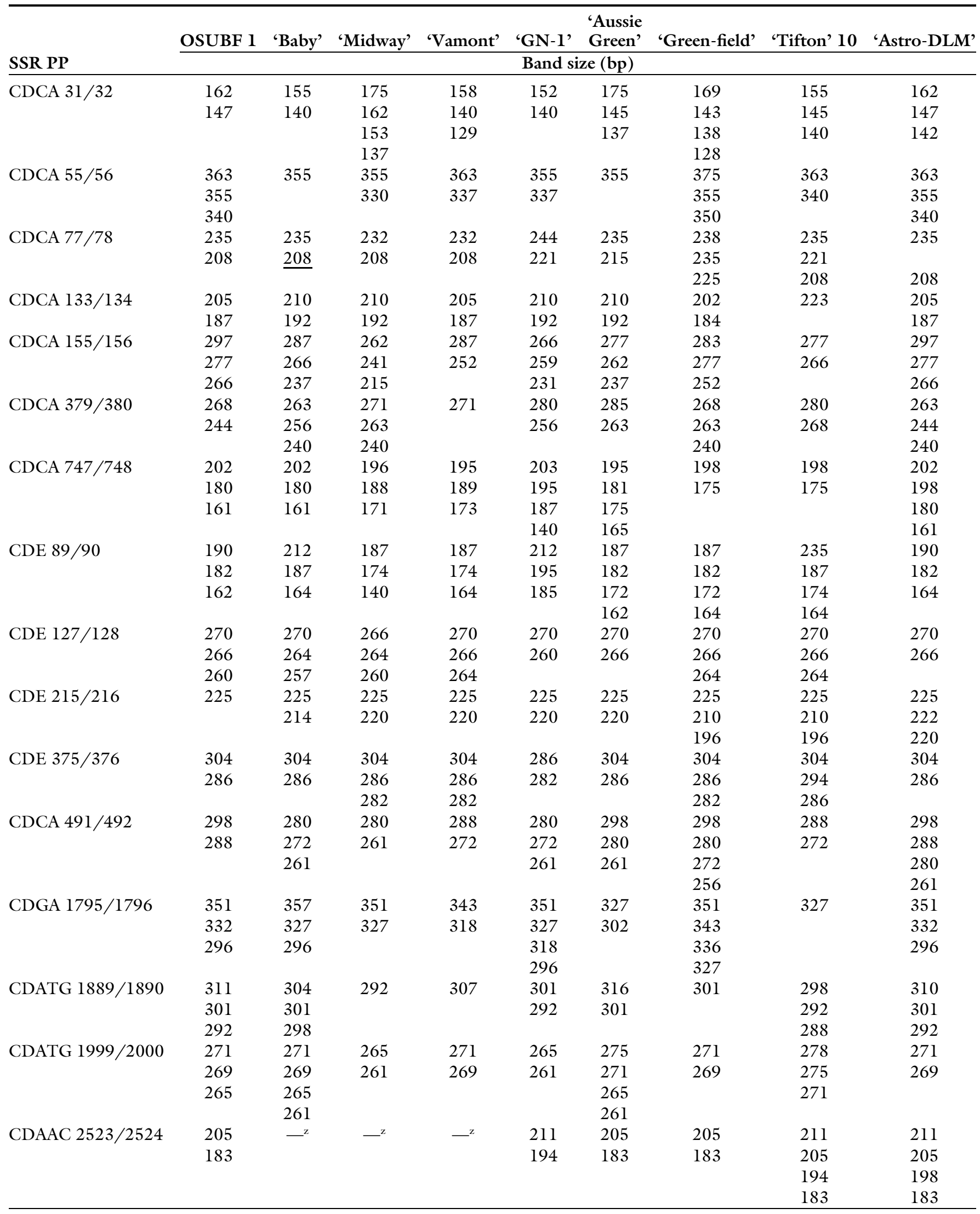

${ }^{\mathrm{z}}$ Failed reaction. 
PCR reactions. Using the eight SSR markers, no differences were detected among the five OSUBF bermudagrass samples (Table 3; Fig. 1). None of the clonal varieties, experimental entries, or single 'Riviera' plants had the same banding patterns as the five OSUBF plants. This indicated that the samples from the OSUBF were the same plant and they were genetically different from the other varieties tested. Cluster analysis results on the SSR data are given in Fig. 1, indicating genetic similarity coefficients between the OSUBF plant and each of the other tested varieties varied from 0.60 to 0.86 . From the genetic profiles of the commercial varieties, the U3 grasses were divided into two groups, U3-NY and U3-SIU were in one group while U3-NC, U3-TGS, and 'Quickstand' were in the other. The U3 grouping results were basically consistent with that of Anderson et al. (2001), but the sample used to represent 'Quickstand' in this study could be a contaminant in our 'Quickstand' plot based on previous report by Wang et al. (2010). Similarly, the grouping of 'Latitude 36' and 'NorthBridge' was in agreement with the findings of Wang et al. (2010).
In the second experiment, the OSUBF plant and eight additional clonal varieties (Baby, Midway, Vamont, GN-1, Aussie Green, Greenfield, Tifton 10, and AstroDLM) were genotyped with 16 SSRs, again with two replications (PCR products' band sizes were shown in Table 4). The OSUBF plant was genetically more distant from the other seven clonal varieties tested than it was from 'Astro-DLM' (Fig. 2). The 'Astro-DLM' plant had the same banding patterns as the OSUBF sample for 14 SSRs, but exhibited different banding patterns for the other two SSR PPsCDCA $31 / 32$ and CDAAC 2523/ 2524 (see sample's labeled band sizes in Table 4 ). The similarity coefficient between OSUBF and 'Astro-DLM' was 0.87 based on the 16 SSRs (Fig. 2). To further discern genetic differentiation between the OSUBF grass and 'AstroDLM', 30 additional SSR PPs [no. 17-46 (Table 2)] were used to genotype the two grasses. Of the 30 SSRs, 15 showed polymorphic banding patterns between the two grasses. Six of them plus CDCA 31/ 32 and CDAAC 2523/2524 are shown in Fig. 3. The SSR marker profiles further indicated that the bermudagrass from the OSUBF was different from 'Astro-DLM'. Although the OSUBF bermudagrass is different from the tested varieties, its origin is unknown. 'Astro-DLM' is a different variety than 'Astro' used in the first experiment with the latter being believed to be a contaminant.

The three OSU experimental clones (OKC 1131, OKC 1163, and OKC 1302) showed different banding patterns from each other. They also showed different banding patterns as compared with the other 24 commercially available varieties, including vegetatively propagated varieties and single plants selected from 'Riviera' (Fig. 1). The three OSU experimental bermudagrasses, four standard clonal varieties (Celebration, Latitude 36, Patriot, and Tifway) in the 2013 NTEP bermudagrass test, and 'NorthBridge' were genotyped with 16 SSR markers (PCR products' band sizes were shown in Table 5 ). The similarity coefficients between the three experimental clones and the other five clonal varieties ranged from 0.53 to 0.78 based on these 16 SSRs (Fig. 4). The results provided strong evidence that these three experimental plants were new bermudagrasses.

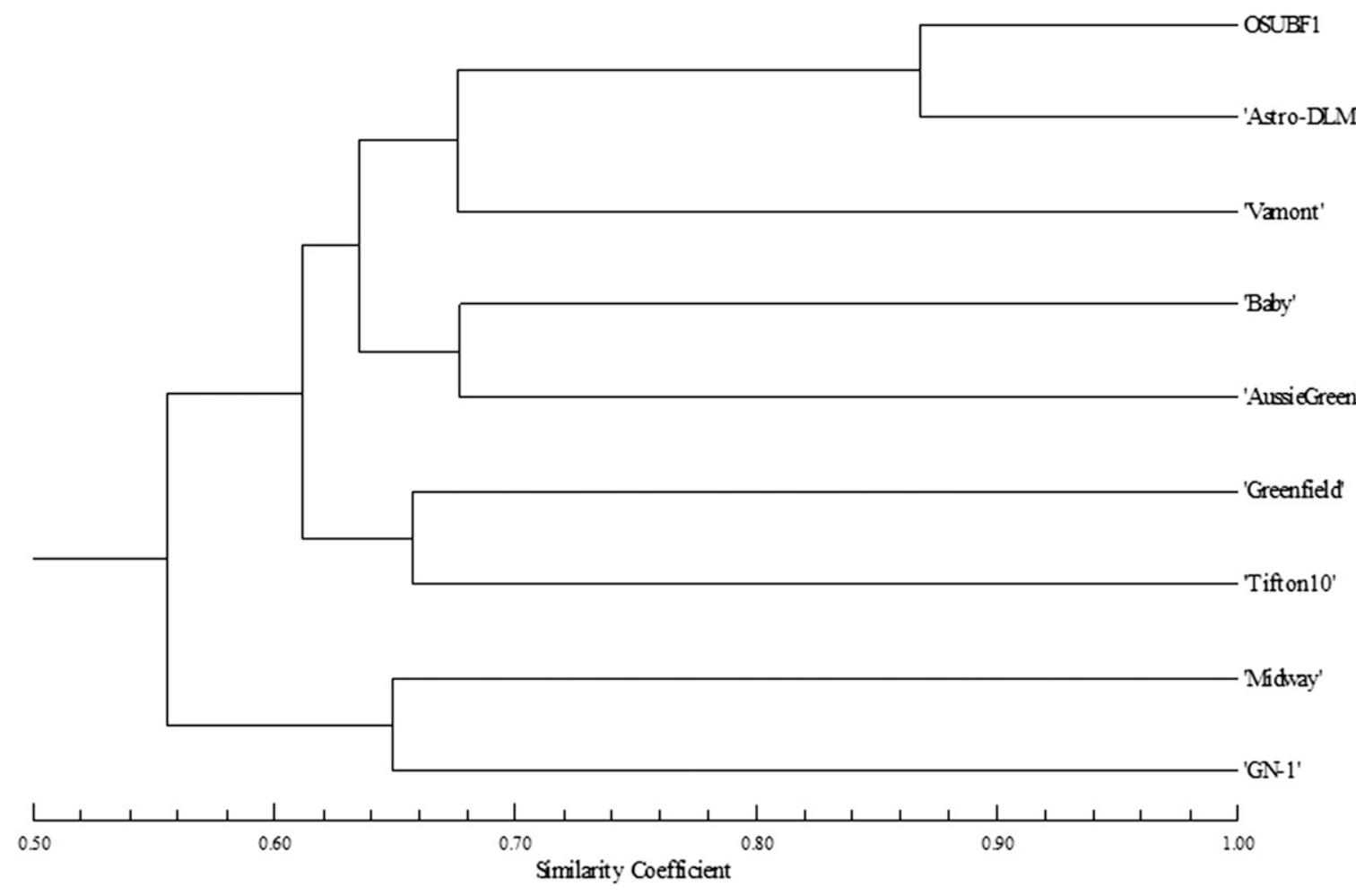

Fig. 2. Dendrogram of the Oklahoma State University Baseball Field (OSUBF) bermudagrass plants and eight additional clonal bermudagrass varieties amplified with 16 simple sequence repeat markers. 


\section{Research Reports}

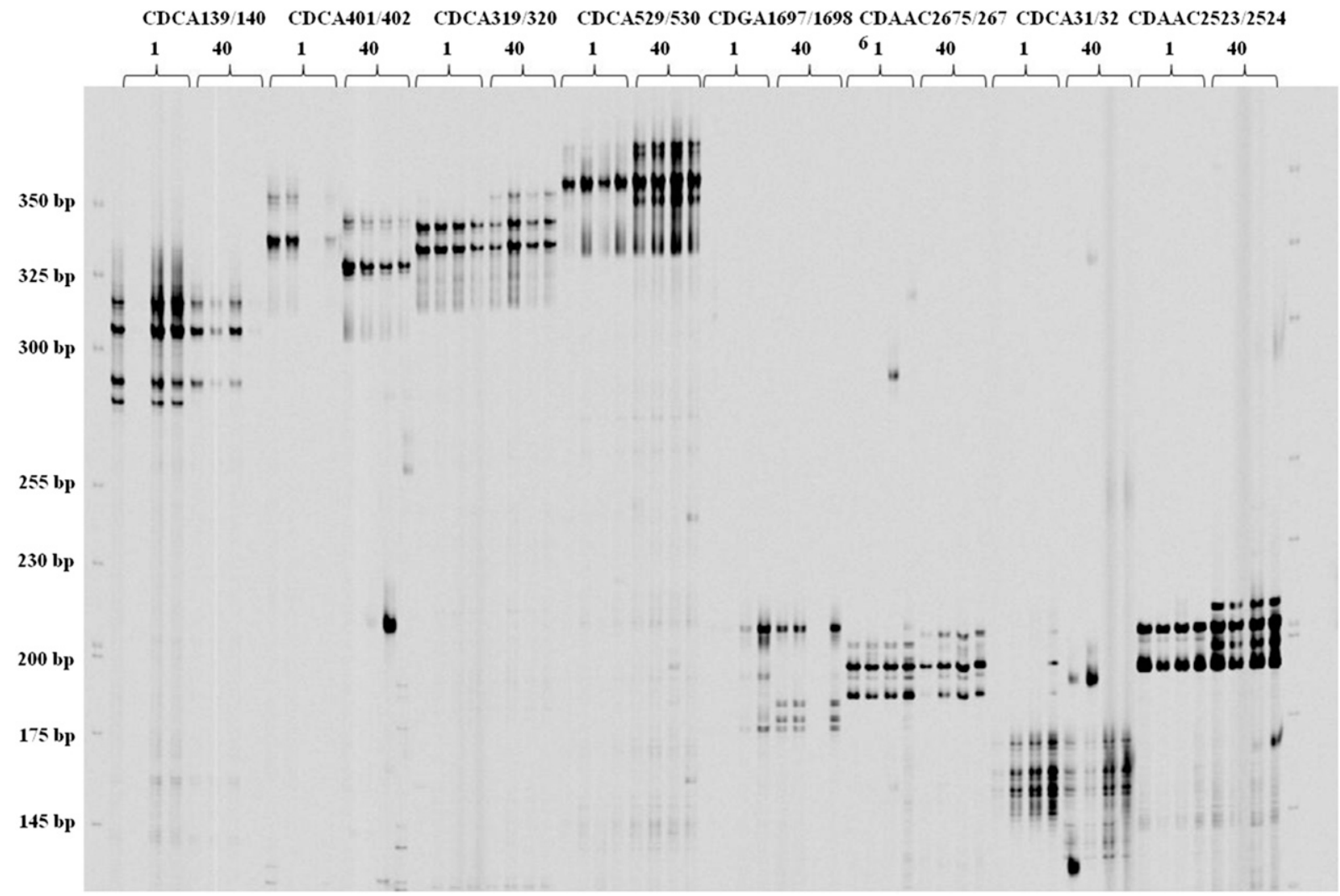

Fig. 3. Polymorphic fingerprints between Oklahoma State University Baseball Field bermudagrass sample (1) and 'Astro-DLM' (40) genotyped with 15 simple sequence repeat (SSR) primer pairs (8 were showed here). Each reaction was replicated four times. SSR markers were given on the top of the gel and under each SSR marker two samples 1 and 40 were labeled. DNA ladder was labeled by base pairs (bp).

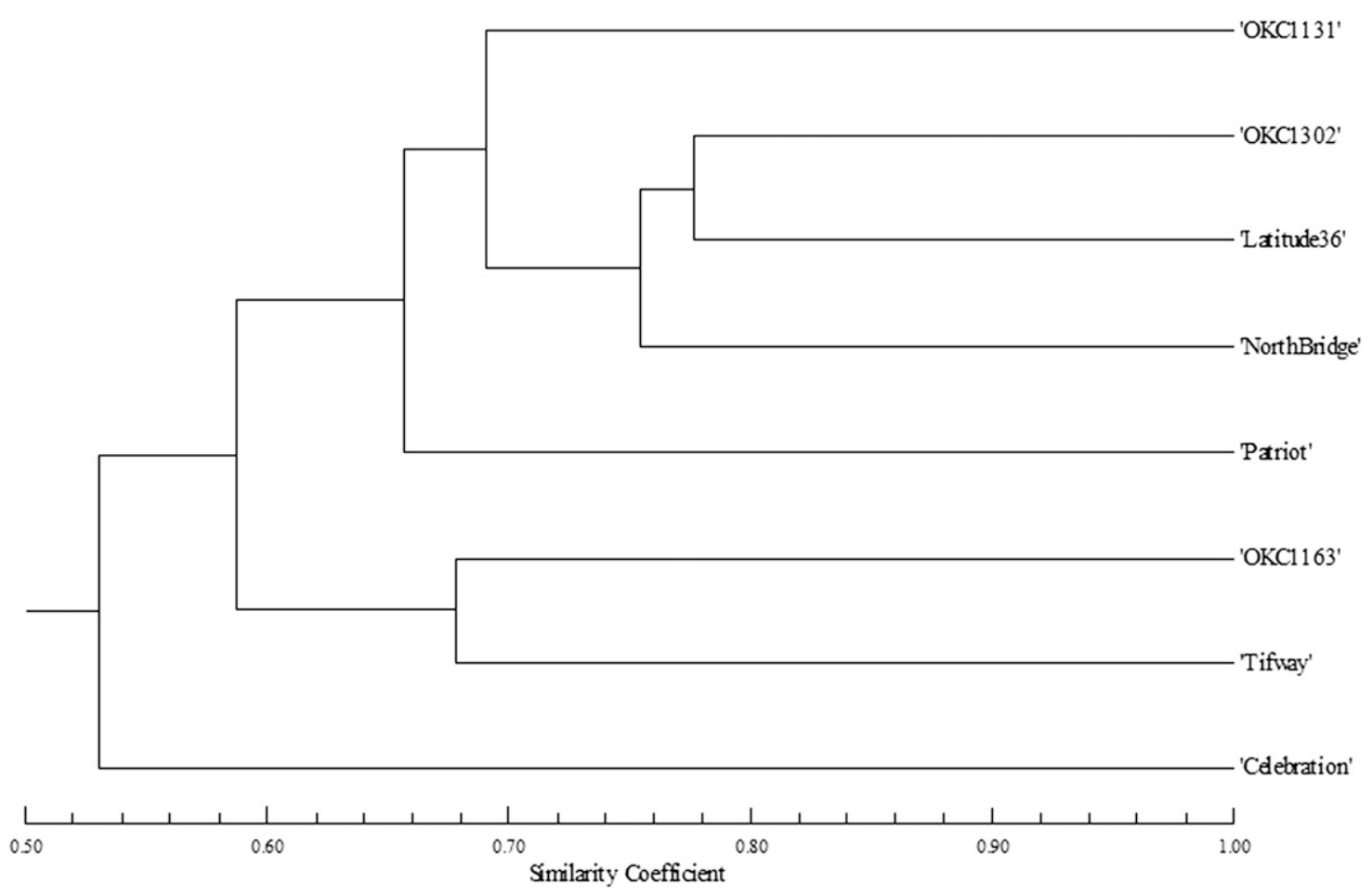

Fig. 4. Dendrogram of three Oklahoma State University bermudagrass experimental varieties and five commercial standard bermudagrass varieties as assessed with 16 simple sequence repeat primer pairs. 
Table 5. Band sizes (in bps) for three Oklahoma State University bermudagrass experimental clones ('OKC 1131', 'OKC 1163', and 'OKC 1302') and five commercial bermudagrass varieties with 16 simple sequence repeat (SSR) primer pairs (PP).

\begin{tabular}{|c|c|c|c|c|c|c|c|c|}
\hline \multirow{2}{*}{ SSR PP } & 'OKC 1131' & 'OKC 1163' & 'OKC 1302' & 'Patriot' & 'OKC 1119' & 'OKC 1134' & 'Tifway' & 'Celebration' \\
\hline & \multicolumn{8}{|c|}{ Band size (bp) } \\
\hline \multirow[t]{3}{*}{ CDCA $31 / 32$} & 184 & 181 & 201 & 174 & 201 & 201 & 184 & 201 \\
\hline & 150 & 174 & 174 & 155 & 174 & 181 & 145 & 202 \\
\hline & & & 152 & 145 & 150 & 154 & & 158 \\
\hline \multirow[t]{4}{*}{ CDCA 55/56 } & 371 & 350 & 356 & 363 & 350 & 356 & 350 & 371 \\
\hline & 356 & 346 & 330 & 346 & 346 & 346 & 346 & 356 \\
\hline & 346 & 330 & & 330 & 330 & 330 & & 346 \\
\hline & 330 & & & & & & & 330 \\
\hline \multirow[t]{4}{*}{ CDCA $77 / 78$} & 294 & 272 & 286 & 294 & 294 & 272 & 263 & 270 \\
\hline & 246 & 263 & 198 & 251 & 263 & 263 & 222 & 263 \\
\hline & 239 & & & 246 & 209 & 209 & 209 & 222 \\
\hline & 199 & & & 199 & & & & 209 \\
\hline \multirow[t]{4}{*}{ CDCA $133 / 134$} & 234 & 208 & 234 & 234 & 251 & 251 & 226 & 234 \\
\hline & 216 & & 216 & 216 & 216 & 216 & 216 & 216 \\
\hline & 208 & & 208 & 208 & 208 & 208 & 208 & 208 \\
\hline & & & & & & & & 204 \\
\hline \multirow[t]{4}{*}{ CDCA $155 / 156$} & 286 & 269 & 330 & 312 & 330 & 286 & 315 & 330 \\
\hline & 269 & 256 & 261 & 286 & 261 & 269 & 302 & 312 \\
\hline & 261 & & 248 & 275 & 248 & 261 & & 304 \\
\hline & & & & & & & & 275 \\
\hline \multirow[t]{3}{*}{ CDCA $379 / 380$} & 304 & 260 & 273 & 267 & 271 & 273 & 287 & 281 \\
\hline & 278 & 255 & 260 & 258 & 260 & 249 & 278 & 271 \\
\hline & 255 & & & & & & 255 & \\
\hline \multirow[t]{4}{*}{ CDCA $747 / 748$} & 193 & 193 & 193 & 193 & 193 & 193 & 193 & 193 \\
\hline & 182 & & & 170 & 170 & & 182 & 182 \\
\hline & 175 & & & 164 & 164 & & & 175 \\
\hline & & & & & & & & 167 \\
\hline \multirow[t]{3}{*}{ CDE $89 / 90$} & 184 & 186 & 184 & 221 & 184 & 186 & 184 & 184 \\
\hline & & 184 & 166 & 184 & 166 & 184 & 174 & 166 \\
\hline & & & & 166 & & 166 & 166 & 154 \\
\hline \multirow[t]{3}{*}{ CDE $127 / 128$} & 267 & 267 & 267 & 267 & 267 & 267 & 267 & 267 \\
\hline & 264 & 259 & 264 & 264 & 264 & 264 & 259 & 264 \\
\hline & 256 & & 259 & 256 & 256 & 256 & & \\
\hline \multirow[t]{3}{*}{ CDE $215 / 216$} & 223 & 220 & 217 & 223 & 223 & 223 & 233 & 215 \\
\hline & 215 & 217 & 215 & 215 & 215 & 215 & 220 & 210 \\
\hline & & & & & & & 215 & \\
\hline \multirow[t]{3}{*}{ CDE $375 / 376$} & 291 & 278 & 293 & 293 & 291 & 291 & 308 & 301 \\
\hline & 283 & & 283 & 283 & 283 & 283 & 301 & 291 \\
\hline & 278 & & 278 & 278 & 278 & 278 & 278 & 283 \\
\hline \multirow[t]{4}{*}{ CDCA $491 / 492$} & 286 & 282 & 286 & 286 & 286 & 286 & 282 & 296 \\
\hline & 282 & 275 & 282 & 282 & 282 & 282 & 275 & 290 \\
\hline & 275 & & 275 & 266 & 266 & 275 & & 275 \\
\hline & & & & & & & & 271 \\
\hline \multirow[t]{2}{*}{ CDGA 1795/1796 } & 365 & 395 & 341 & 341 & 341 & 365 & 341 & 341 \\
\hline & 316 & & 316 & 325 & 316 & 316 & & 325 \\
\hline \multirow[t]{4}{*}{ CDATG 1889/1890 } & 317 & 302 & 317 & 302 & 317 & 308 & 294 & 302 \\
\hline & 308 & 294 & 308 & 294 & 308 & 294 & 290 & 290 \\
\hline & 302 & & 302 & & 302 & & & \\
\hline & 294 & & 294 & & 294 & & & \\
\hline \multirow[t]{2}{*}{ CDATG 1999/2000 } & 280 & 270 & 280 & 280 & 280 & 280 & 285 & 285 \\
\hline & 270 & & 274 & 274 & & 270 & 270 & \\
\hline CDAAC $2523 / 2524$ & 216 & 207 & 207 & 207 & 207 & 207 & 216 & $一^{\mathrm{z}}$ \\
\hline
\end{tabular}

${ }^{\mathrm{z}}$ Failed reaction.

In summary, SSR genotyping data in this investigation indicated the OSUBF bermudagrass plants were identical. The SSR data further indicated the OSUBF plant and three
OSU experimental clones were different from each other and from all tested varieties. Each of the four clonal bermudagrasses has the potential to be released as a new variety if they are clearly superior to existing varieties in one or more important characteristics or a combination of characteristics for turf performance and adaptation. 


\section{Literature cited}

Alderson, J. and W.C. Sharp. 1994. Grass varieties of the United States. U.S. Dept. Agr., Agr. Hdbk. 170.

Anderson, M.P., C.M. Taliaferro, D.L. Martin, and C.S. Anderson. 2001. Comparative DNA profiling of U-3 turf bermudagrass strains. Crop Sci. 41:11841189.

Baldwin, C.M., H. Liu, L.B. McCarty, and W.L. Bauerle. 2006. Response of six bermudagrass varieties to different irrigation intervals. HortTechnology 16:466470 .

Brosnan, J.T. and J. Deputy. 2008. Bermudagrass. Turf management (revised). Univ. of Hawaii at Manoa TM-5.

Burton, G.W. 1966. Tifway (Tifton 419) bermudagrass (Reg. No. 7). Crop Sci. 6:93-94.

de los Reyes, B.G., C.M. Taliaferro, M.P. Anderson, J.A. Anderson, U. Melcher, and S. McMaugh. 2001. Induced expression of the class II chitinase gene during cold acclimation and dehydration of bermudagrass (Cynodon sp.). Theor. Appl. Genet. 103:297-306.

Hanna, W.W., G.W. Burton, and A.W. Johnson. 1990. Registration of 'Tifton
10' turf bermudagrass. Crop Sci. 30:1355-1356.

Harris-Shultz, K.R., B.M. Schwartz, and J.A. Brady. 2011. Identification of simple sequence repeat markers that differentiate bermudagrass cultivars derived from 'Tifgreen'. J. Amer. Soc. Hort. Sci. 136:211-218.

Juska, F.V. and A.A. Hanson. 1964. Evaluation of bermudagrass varieties for general purpose turf. U.S. Dept. Agr., Agr. Hdbk. 270.

Nalini, E. and N. Jawali. 2004. A simple method for isolation of DNA from plants suitable for long term storage and DNA marker analysis. BARC Nwsl. 249:208214.

Pair, J.C., R.A. Keen, C.M. Taliaferro, D.L. Martin, J.F. Barber, and R.N. Carrow. 1994a. Registration of 'Midlawn' turf bermudagrass. Crop Sci. 34:306-307.

Pair, J.C., R.A. Keen, C.M. Taliaferro, D.L. Martin, J.F. Barber, and R.N. Carrow. 1994b. Registration of 'Midfield' turf bermudagrass. Crop Sci. 34:307.

Parsons, D.L.V. and V.G. Lehman. 2007. Bermudagrass plant named 'Premier'. U.S. patent PP18247 P3. 7 Nov. 2014. <http://www.freepatentsonline.com/ PP18247.html>.
Phillips, T.D., D.P. Belesky, and A.J. Powell, Jr. 1997. Registration of 'Quickstand' bermudagrass. Crop Sci. 37:1674.

Porter, W.E. 1997. Bermudagrass plant TDS-BMl. U.S. patent PP09976. 7 Nov. 2014. <http://www.freepatentsonline. com/PP09976.html>.

Riley, R.J. 2000. Cynodon dactylon plant named 'Riley's Super Sport'. U.S. patent PP11181. 7 Nov. 2014. <http://www. freepatentsonline.com/PP11181.html>.

Rohlf, F.J. 2000. NTSYS-PC version 2.10s. Numerical taxonomy and multivariate analysis system. Exeter Publ., Setauket, NY.

Taliaferro, C.M., D.L. Martin, J.A. Anderson, M.P. Anderson, and A.C. Guenzi. 2004a. Broadening the horizons of turf bermudagrass. USGA Turfgrass Environ. Res. 3(2):1-9.

Taliaferro, C.M., D.L. Martin, J.A. Anderson, and M.P. Anderson. 2004b. Patriot turf bermudagrass. U.S. PP16801 P2. 7 Nov. 2014 . <http://www. freepatentsonline.com/PPl6801.html>.

Wang, Z., Y.Q. Wu, D.L. Martin, H.W. Gao, T. Samuels, and C.C. Tan. 2010. Identification of vegetatively propagated turf bermudagrass cultivars using simple sequence repeat markers. Crop Sci. 50:2103-2111. 